\title{
PENGEMBANGAN VIRTUAL REALITY PENDETEKSI KERUSAKAN MESIN KENDARAAN OFF THE ROAD FIN KOMODO
}

\author{
Hennry Poerwanto B. 1), Muhammad Taufiq ${ }^{2}$ \\ 1) Program Studi Sistem Informasi FIK Universitas Amikom Yogyakarta \\ 2) Program Studi Pendidikan Teknologi Informasi FKIP UMTAS \\ email: hennry@amikom.ac.id ${ }^{1)}$, mtaufiq@umtas.ac.id $^{2)}$
}

\begin{abstract}
With the increasing of technological advancements, it also influences the development of mobile devices today, so that mobile devices are increasingly popular in the community. This development is very helpful in presenting information quickly and efficiently by accessing the internet through these mobile devices. Although a mobile device is a small device with a very limited display screen, the presentation is no less optimal than information accessed through a personal computer, depending on how it is presented. Virtual Reality (VR) is one part of artificial intelligence that contains the knowledge and experience that is entered by experts into a particular knowledge area so that everyone can use it to solve a variety of specific problems in this case is the problem with the engine maintenance of Fin Komodo.
\end{abstract}

Keywords: Virtual Reality, Engine Maintenance, Android

\begin{abstract}
Abstraksi
Meningkatnya kemajuan teknologi saat ini, mempengaruhi perkembangan perangkat mobile, sehingga perangkat seluler semakin populer di masyarakat. Perkembangan ini sangat membantu dalam menyajikan informasi secara cepat dan efisien dengan mengakses internet melalui perangkat mobile. Meskipun perangkat seluler adalah perangkat kecil dengan tampilan layar yang sangat terbatas, presentasi tidak kurang optimal dari informasi yang diakses melalui komputer pribadi, tergantung pada bagaimana disajikan. Virtual Reality (VR) adalah salah satu bagian dari kecerdasan buatan yang berisi pengetahuan dan pengalaman yang dimasukkan oleh para ahli ke dalam bidang pengetahuan tertentu sehingga setiap orang dapat menggunakannya untuk memecahkan berbagai masalah spesifik, dalam hal ini adalah masalah perawatan mesin Fin Komodo.
\end{abstract}

Kata Kunci: Virtual Reality, Engine Maintenance, Android

\section{Pendahuluan}

Fin Komodo adalah kendaraan off the road hasil karya buatan putra terbaik bangsa Indonesia Ir. Ibnu Susilo dalam satu dekade terakhir ini. Hasil karya ini kemudian oleh BPPT dianugrahi Habibie Award 2017 (http://www.finkomodo.com; http://www.bppt.go.id). Meskipun demikian, dengan status kendaraan off the road, medan kerja kendaraan sangat berat, dari medan terjal berbatu, padang, sawah, hutan, tebing, dan lain-lain, mengakibatkan mesin Fin Komodo sering mengalami kerusakan. Kerusakan pada mesin Fin Komodo terjadi akibat kelalaian dalam melakukan perawatan. Pemilik Fin Komodo baru menyadari kerusakan setelah Fin Komodo tidak dapat beroperasi sebagaimana mestinya. Oleh karena itu dalam penggunaan Fin Komodo kemungkinan besar membutuhkan perawatan berkala, hal inilah yang mendorong pengembangan Virtual Reality [1] untuk mengidentifikasi kerusakan mesin Fin Komodo.

Virtual Reality (VR) adalah sistem berbasis komputer yang menggunakan pengetahuaan, fakta dan teknik penalaran dalam memecahkan masalah yang biasanya hanya dapat dipecahkan oleh seorang cerdas dalam bidang tersebut [1]. Pada dasarnya Virtual Reality diterapkan untuk mendukung aktivitas pemecahan masalah. Beberapa aktivitas pemecahan yang dimaksud antara lain: pembuatan keputusan (decision making), pemanduan pengetahuan (knowledge fusing), pembuatan desain (designing), perencanaan (planning), prakiraan (forecasting), pengaturan (regulating), pengendalian (controlling), diagnosis (diagnosing), perumusan (prescribing), penjelasan (explaining), pemberian nasihat (advising) dan pelatihan (tutoring). Selain itu Virtual Reality juga dapat berfungsi sebagai asisten yang pandai dari seorang cerdas [2].

Virtual Reality dibuat pada wilayah pengetahuan tertentu untuk suatu kecerdasan tertentu yang mendekati kemampuan manusia disalah satu bidang. Virtual Reality mencoba mencari solusi yang memuaskan sebagaimana yang dilakukan oleh seorang cerdas. Selain itu Virtual Reality juga dapat memberikan penjelasan terhadap langkah yang diambil dan memberikan alasan atas saran atau kesimpulan yang ditemukannya. Biasanya Virtual Reality 
hanya digunakan untuk memecahkan masalah yang memang sulit untuk dipecahkan dengan pemrograman biasa, mengingat biaya yang diperlukan untuk membuat Virtual Reality jauh lebih besar dari pembuatan sistem biasa [1] [3].

Secara umum, Virtual Reality adalah sistem yang berusaha mengadopsi pengetahuan manusia ke komputer yang dirancang untuk memodelkan kemampuan menyelesaikan masalah seperti layaknya seorang cerdas. Dengan Virtual Reality ini, orang awam pun dapat menyelesaikan masalahnya atau sekedar mencari suatu informasi berkualitas yang sebenarnya hanya dapat diperoleh dengan bantuan para ahli di bidangnya. Virtual Reality ini juga akan dapat membantu aktivitas para cerdas sebagai asisten yang berpengalaman dan mempunyai pengetahuan yang dibutuhkan [1] [4].

Dalam penyusunannya, Virtual Reality mengkombinasikan kaidah-kaidah penarikan kesimpulan (inference rules) dengan knowledge base tertentu yang diberikan oleh satu atau lebih, cerdas dalam bidang tertentu. Kombinasi dari kedua hal tersebut disimpan dalam komputer, yang selanjutnya digunakan dalam pengambilan keputusan untuk penyelesaian masalah tertentu. Virtual Reality yang baik harus memenuhi ciri-ciri sebagai berikut: a) Terbatas pada bidang yang spesifik; b) dapat memberikan penalaran untuk data-data yang tidak lengkap atau tidak pasti; c) dapat mengemukakan rangkaian alasan yang diberikan dengan cara yang dapat dipahami; d) berdasarkan rule atau kaidah tertentu; e) dirancang untuk dapat dikembangkan secara bertahap; f) outputnya bersifat nasihat atau anjuran; g) output tergantung dari dialog dengan user; h) knowledge base dan inference engine terpisah; i) dapat digunakan dalam berbagai jenis computer [5].

Secara garis besar, banyak manfaat yang dapat diambil dengan adanya Virtual Reality, antara lain: a) memungkinkan orang awan bisa mengerjakan pekerjaan para ahli; b) bisa melakukan proses secara berulang secara otomatis; c) menyimpan pengetahuan dan keahlian para cerdas; d) meningkatkan output dan produktivitas; e) meningkatkan kualitas; f) mampu mengambil dan melestarikan keahlian para cerdas (terutama yang termasuk keahlian langka); g) mampu beroperasi dalam lingkungan yang berbahaya; h) memiliki kemampuan untuk mengakses pengetahuan; i) memiliki reliabilitas; j) meningkatkan kapabilitas sistem computer; k) memiliki kemampuan untuk bekerja dengan informasi yang tidak lengkap dan mengandung ketidakpastian; 1) sebagai media pelengkap dalam pelatihan; m) meningkatkan kapabilitas dalam penyelesaian masalah; n) menghemat waktu dalam pengambilan keputusan [6].

Disamping memiliki beberapa keuntungan, Virtual Reality juga memiki beberapa kelemahan, antara lain: a) masalah dalam mendapatkan pengetahuan yaitu pengetahuan tidak selalu bisa didapatkan dengan mudah, karena kadangkala cerdas dari masalah yang kita buat tidak ada dan kalaupun ada kadang-kadang pendekatan yang dimiliki oleh cerdas berbeda-beda; b) untuk membuat suatu Virtual Reality yang benar-benar berkualitas tinggi sangatlah sulit dan memerlukan biaya yang sangat besar untuk pengembangan dan pemeliharaannya; c) boleh jadi sistem tak dapat membuat keputusan; d) Virtual Reality tidaklah 100\% menguntungkan, walaupun seorang tetap tidak sempurna atau tidak selalu benar. Oleh karena itu perlu diuji ulang secara teliti sebelum digunakan. Dalam hal ini peran manusia tetap merupakan faktor dominan [1].

Virtual Reality sendiri dikembangkan lebih lanjut dengan alasan: a) dapat menyediakan kecerdasan setiap waktu dan berbagai lokasi; b) secara otomatis mengerjakan tugas-tugas rutin yang membutuhkan seorang cerdas; c) seorang cerdas akan pensiun atau pergi; d) seorang cerdas adalah mahal; e) kecerdasan dibutuhkan juga pada lingkungan yang tidak bersahabat. Penyampaian informasi pun dilakukan menggunakan perangkat mobile dengan meminta request dari user. Request tersebut akan diproses dalam sistem kemudian hasilnya akan dikirim lagi ke user dengan ditampilkan pada layar perangkat mobile. Diharapkan sistem ini mampu memberikan informasi yang optimal dari timbal balik user dan system [5].

Penelitian ini ditujukan untuk mengembangkan Virtual Reality guna mendiagnosa penyebab kerusakan mesin Fin Komodo berbasiskan Android adalah agar pengguna dapat mengetahui penyebab kerusakan mesin Fin Komodo dengan memanfaatkan fasilitas Android sebelum Fin Komodo dibawa ke bengkel. Penelitian ini juga memberikan manfaat menambah motivasi dan inspirasi untuk mengembangkan software-software yang lebih baik, efektif dan efisien.

\section{Metode Penelitian}

\section{Desain Penelitian}

Penelitian ini mendesain sistem aplikasi yang akan dirancang dan agar dapat mengidentifikasi komponenkomponen sistem informasi yang akan didesain secara rinci. Tahap ini dilakukan setelah tahap analisis sistem selesai dilaksanakan. Desain aplikasi ini meliputi flowchart atau teknik lain seperti sketsa dan lain-lain dalam mendukung desain system.

\section{Metode Pengumpulan Data}

Pengumpulan data dilakukan dengan pengambilan sampel data, yaitu: 
1. Data Primer, merupakan data yang dikumpulkan oleh orang atau perseorangan secara langsung dari sumbernya. Contoh pengambilan data berupa teks hasil wawancara yang diperoleh melalui wawancara dengan informan yang dijadikan sampel penelitian. Data dapat direkam atau dicatat oleh peneliti.

2. Data Sekunder, merupakan data yang tidak diperoleh secara langsung dari objek peneltian. Contoh pengambilan data berupa data-data yang sudah tersedia dan dapat diperoleh peneliti dengan cara membaca, melihat atau mendengarkan. Termasuk dalam kategori data ini ialah: data bentuk teks (dokumen, surat-surat), bentuk gambar (foto, animasi), bentuk suara (hasil rekaman kaset) dan kombinasi teks, gambar dan suara (film, video).

3. Metode dokumentasi, yaitu suatu teknik pengumpulan data dengan cara menggunakan arsip atau naskahnaskah tertulis.

4. Studi pustaka, merupakan teknik pengumpulan data dengan cara mencari referensi-referensi dari buku-buku atau literatur yang membahas mengenai objek yang akan diteliti.

\section{Metoda Analisis Data}

Setelah sistem dianalisis dan didesain secara rinci dan teknologi telah diseleksi dan dipilih, tahap implementasi sistem merupakan tahap meletakkan sistem supaya siap untuk dioperasikan. Tahap ini termasuk juga kegiatan pembuatan aplikasi program. Tahap implementasi sendiri dibagi dalam tiga tahap yaitu: a) menerapkan rencana implementasi; b) melakukan kegiatan implementasi; c) tindak lanjut implementasi.

Uji coba sistem dilakukan untuk mencari kesalahan atau kekurangan dari program atau aplikasi yang dibuat agar dapat dicapai tujuan yang diinginkan dan uji coba ini dapat langsung diaplikasikan di lapangan. Selanjutnya secara lebih terperinci dijelaskan dalam pengujian baik user umum maupun admin, beserta langkah-langkah dalam uji coba tersebut, kemudian dianalisis kembali apakah telah sesuai dengan tujuan penelitian.

\section{Hasil dan Pembahasan}

Perancangan sistem dimulai dengan mengidentifikasi permasalahan hingga pengujian. Secara garis besar ada 4 tahap yaitu identifikasi, konseptualisasi, formalisasi atau rancangan dan pengujian. Dikarenakan tiap-tiap tahap saling berhubungan dan saling menunjang, maka tahap-tahap tadi harus dikerjakan secara berurutan satu sama lain. Sistem sederhana yang akan dirancang ini merupakan bagian kecil dari sistem analisis secara keseluruhan. Sedangkan permasalahan spesifik yang akan diangkat adalah mengenai kerusakan mesin Fin Komodo mulai dari bagian-bagian mesin, macam kerusakan yang sering dialami dan penyebab gangguan pada mesin (http://finkomodo.com).

1. Tahap Identifikasi. Pada tahap ini pengidentifikasian permasalahan yang akan dibuat Virtual Reality berkaitan dan terbatas pada kerusakan mesin. Knowledge engineer harus menentukan batasan-batasan permasalahan yang bersifat spesifik dan bersifat umum tentang bagian-bagian mesin dan troubleshooting yang sering timbul pada bagian-bagian tersebut (http://finkomodo.com).

2. Tahap Konseptualisasi. Dalam tahap konseptualisasi ini ditentukan unsur-unsur apa saja yang terkait dari bagian gejala-gejala serta penyebab yang biasa ditimbulkan. Berikut ini adalah bagian mesin dan permasalahan yang disajikan dalam pembuatan program (http://finkomodo.com).

- Starter tidak berputar. Penyebab gangguan: terminal kabel batere kendor, batere lemah, tali kipas kendor, sekring utama konslet, kunci kontak atau relay starter rusak, magnetic switch rusak, starter motor rusak.

- Starter motor berputar tetapi mesin tidak hidup. Penyebab gangguan: terminal kabel batere kendor, batere lemah, tali kipas kendor, gigi pinion rusak, magnetic switch rusak, brush aus, piston, bearing poros engkol aus.

- Mesin berputar tetapi tidak hidup. Penyebab gangguan: katup solenoid rusak.

- Bahan bakar tidak mengalir ke pompa injeksi. Penyebab gangguan: tangki bahan bakar kosong, pipa bahan bakar tersumbat, katup over flow pada saringan bahan bakar tidak tertutup, saringan bahan bakar tersumbat, ada udara di dalam sistem bahan bakar, feed pump rusak, penggunaan bahan bakar salah, ada air di dalam sistem bahan bakar, ada udara di dalam pompa injeksi, nozzle pengabut rusak, tekanan nozzle terlalu rendah, plunger pada pompa injeksi aus, poros penggerak pompa injeksi aus, pegas governor pompa injeksi aus.

- Putaran stasioner tidak rata. Penyebab gangguan: penyetelan putaran stasioner tidak tepat, alat pengontrol putaran fast idle rusak, sistem pengontrol akselerasi penyetelan tidak tepat, sistem bahan bakar tersumbat, ada udara di dalam sistem bahan bakar, ada air di dalam sistem bahan bakar, element saringan bahan bakar tersumbat, feed pump rusak, nozzle pengabut rusak, tekanan nozzle terlalu rendah, delivery valve rusak, timing penyetelan tidak tepat, volume pengabutan tidak cukup, pegas idle rusak, lever governor 
rusak, regulator valve penyetelan tidak tepat, spring plunger rusak, plunger rusak, cam disk aus, celah katup penyetelan tidak tepat, gasket kepala silinder aus.

- Tenaga kurang. Penyebab gangguan: saringan udara tersumbat, ada air di dalam bahan bakar, saringan bahan bakar tersumbat, feed pump rusak, nozzle pengabut rusak, tekanan nozzle terlalu rendah, pipa tekanan tinggi rusak, regulating valve rusak, cam disk aus, bekerjanya control lever tidak tepat, timing rusak, spring governor rusak, gasket kepala silinder terbakar, pegas katup lemah, pipa pembuangan tersumbat, seal baut penyetel tidak tepat.

- Bahan bakar boros. Penyebab gangguan: bahan bakar bocor, elemen saringan tersumbat, setelan putaran stasioner tidak tepat, tekanan nozzle terlalu rendah, setelan timing tidak tepat, delivery valve rusak, penyetelan katup tidak tepat, gasket kepala silinder terbakar, pegas katup lemah.

- Oli boros. Penyebab gangguan: oli mesin tidak baik, oli bocor dari oil seal, air breather tersumbat, valve quide dan valve stem aus.

- Mesin panas. Penyebab gangguan: air pendingin kurang, oli bocor dari fan coupling, tali kipas kendor, tutup radiator rusak atau radiator core tersumbat, pompa air rusak, sealing cap rusak, sistem pendinginan tersumbat oleh kotoran, penyetelan timing pengabutan bahan bakar tidak tepat.

- Asap gas buang putih. Penyebab gangguan: ada air dalam bahan bakar, timing pengabutan bahan bakar tidak tepat, gasket kepala silinder terbakar, seal katup rusak, valve stem dan valve quide aus.

- Asap gas buang hitam. Penyebab gangguan: saringan udara tersumbat, tekanan nozzle terlalu rendah, timing tidak tepat, delivery valve rusak, volume pengabutan terlalu banyak

- Tekanan oli tidak naik. Penyebab gangguan: kekentalan oli mesin tidak baik, oli mesin kurang, meter tekanan oli rusak, relief valve aus atau spring bypass valve lemah, saringan pompa oli tersumbat, bagian yang berhubungan dengan pompa oli aus, bushing rocker arm aus, camshaft dan bearing camshaft aus, poros engkol dan bantalan aus.

- Engine knocking. Penyebab gangguan: bahan bakar tidak baik, penyetelan timing tidak tepat, tekanan nozzle dan kondisi pengabutan, gasket terbakar dan piston ring aus.

- Bunyi kebocoran gas. Penyebab gangguan: pipa exhaust sambungan kendor, pipa exchange rusak, nozzle dan atau glow plug kendor, sambungan exhaust manifold dan atau glow plug kendor, gasket kepala silinder rusak.

- Bunyi suara kontinyu. Penyebab gangguan: kendorkan tali kipas, kipas pendingin kendor, aus atau rusak bearing pompa air, alternator atau pompa vacuum rusak, celah katup setelannya tidak tepat.

- Suara benturan (Slapping noise). Penyebab gangguan: penyetelan katup tidak tepat, rocker arm rusak, baut fly wheel kendor, crankshaft dan atau conneting rod bearing aus atau rusak, connecting rod bushing dan piston pin aus atau rusak, piston dan silinder liner aus atau rusak.

Data di atas adalah data tentang berbagai kerusakan mesin pada Fin Komodo beserta penyebab gangguan yang ditimbulkannya. Data tersebut merupakan data awal sebagai inputan dari sistem sebelum diproses menjadi data output.

3. Tahap Rancangan. Pada tahap rancangan ini semua permasalahan yang saling berelasi atau berhubungan akan diformulasikan sesuai dengan software/ bahasa pemrograman yang akan digunakan untuk memaparkan hubungan relasional tersebut sesuai dengan bentuk format yang digunakan oleh sistem analisis. Dalam tahap ini sering disebut juga knowledge base [7].

4. Tahap Pengujian. Sistem yang telah selesai akan diuji. Apabila sistem yang telah dibentuk ini masih kurang optimal, maka akan dilakukan perbaikan-perbaikan sampai semua permasalahan dapat teratasi, lengkap dan akurat. Sistem yang telah diperbaiki akan diuji kembali sampai sistem itu benar-benar lengkap dan akurat serta layak digunakan [8]. 
5. Desain Algoritma untuk Pencarian Data. Untuk desain algoritmanya digambarkan dalam sebuah diagram berikut ini:

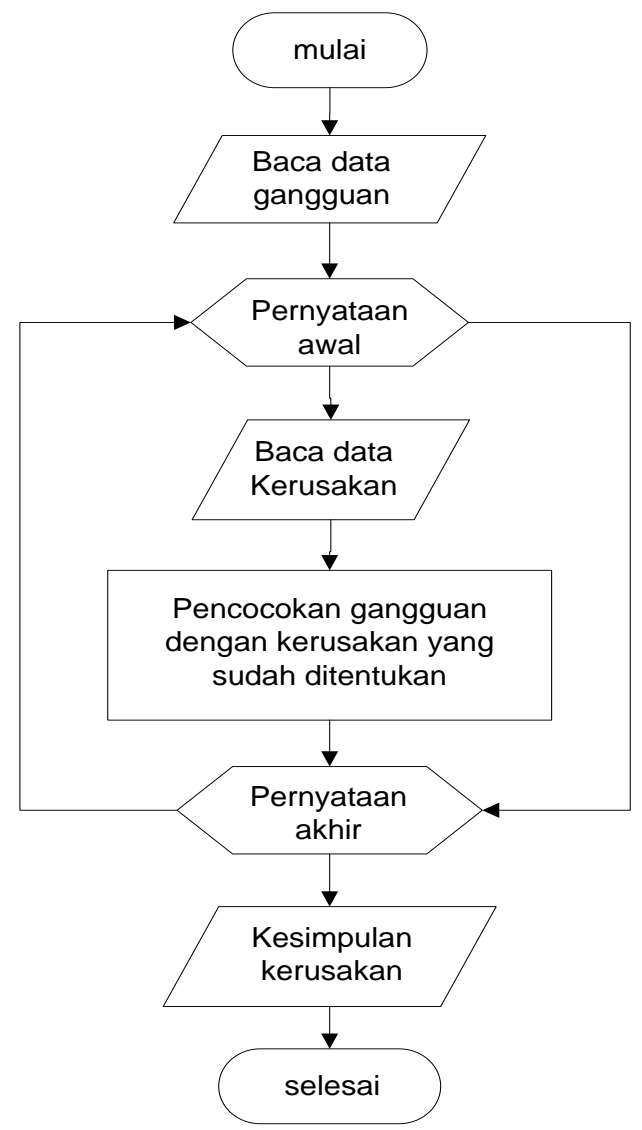

Gambar 1: Algoritma pencarian data [9]

6. Pemilihan Mekanisme Inferensi. Mekanisme inferensi adalah bagian dari Virtual Reality yang melakukan penelusuran dengan menggunakan isi daftar aturan berdasarkan urutan pola tertentu. Selama proses konsultasi antar sistem dan pemakai, mekanisme inferensi menguji aturan satu demi satu sampai kondisi aturan itu benar. Secara umum ada dua teknik utama yang digunakan dalam mekanisme inferensi untuk pengujian aturan, yaitu penulusuran maju (forward chaining) dan penulusuran mundur (backward chaining) [1]. Dalam penulusuran maju, aturan-aturan yang diuji satu demi satu dalam urutan tertentu. Urutan ini mungkin berupa urutan pemasukan aturan ke dalam basis aturan atau juga urutan lain yang ditentukan oleh pemakai. Saat tiap aturan diuji, Virtual Reality akan mengevaluasi apakah kondisinya benar atau salah. Jika kondisi benar maka aturan itu disimpan kemudian aturan itu diuji. Namun jika kondisinya salah, aturan itu tidak disimpan dan aturan berikutnya akan diuji. Proses ini akan berulang sampai seluruh basis aturan teruji dengan berbagai kondisi [9]. Dalam mencari kerusakan mesin dan mencari penyebab gangguan mesin akan dimulai dengan memberikan pertanyaan mengenai gangguan yang dialami atau dengan memberikan daftar macam kerusakan sehingga diperoleh suatu diagnosa kerusakan dan hasil akhir kesimpulan kerusakan mesin tersebut [8]. Proses pelacakan kedepan (forward chaining) pada sistem analisis kerusakan mesin secara umum dapat digambarkan sebagai berikut: 


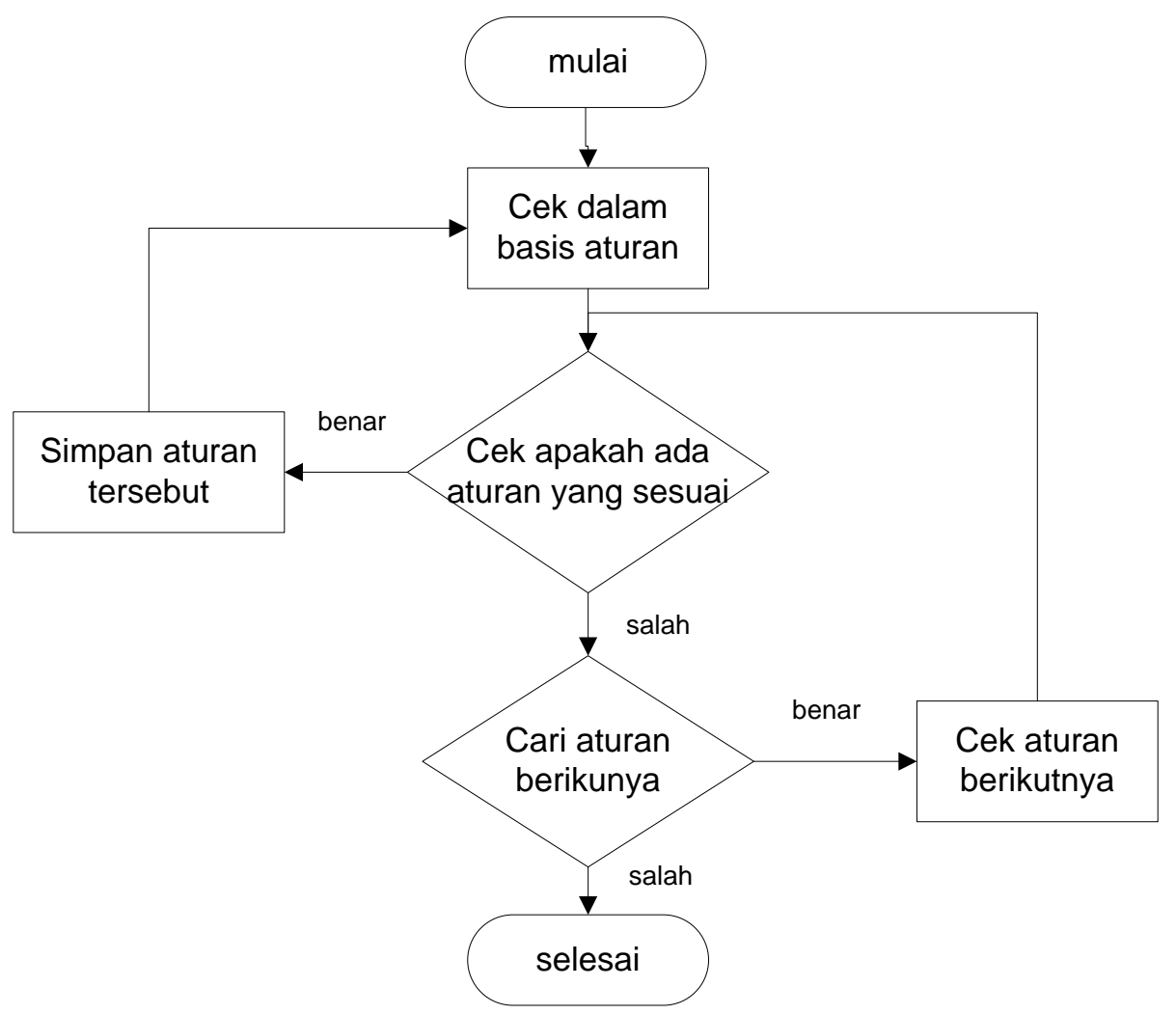

Gambar 2: Proses pelacakan ke depan [8]

7. Pemilihan Metode Penelusuran. Teknik penelusuran ada tiga yaitu depth firsth search, breath first search dan best first search. Metode penelusuran yang digunakan dalam perancangan sistem ini menggunakan breath first search sebagai metode pelacakan untuk mencapai suatu tujuan. Proses ini bekerja dari kiri ke kanan baru bergerak ke bawah. Hal ini akan berlanjut sampai ditemukan titik tujuan [10].

8. Knowledge base. Knowledge base merupakan tempat penyimpanan pengetahuan yang berupa informasi dari domain aplikasi dan menyediakan untuk sistem. Informasi dalam knowledge base dimasukkan dalam sebuah program komputer dengan proses yang disebut representasi pengetahuan. Simpanan pengetahuan ini berupa fakta dan aturan. Fakta dan aturan disimpan dalam bentuk database. Database ini berisi rangkaian informasi tentang status masalah yang sudah dipecah-pecah. Fakta direpresentasikan dengan menetapkan kesesuaian antara representasi internal fakta dengan representasi bahasa alami. Aturan ini berisi tentang bagaimana menggunakan pengetahuan untuk memecahkan masalah khusus pada setiap domain. Aturan pada knowledge base direpresentasikan sebagai perintah berpasangan atau sebagai IF kondisi THEN aksi. Bagian IF mendiskripsikan representasi situasi pasti berupa kumpulan dari pernyataan. Aturan ini digunakan oleh cognitive system [11].

Knowledge base memperoleh pengetahuan dari system cerdas dan atau sumber dokumen lainnya. Pengetahuan yang masih menggunakan bahasa alami ini harus dibawa ke bahasa yang dimengerti computer [12]. 


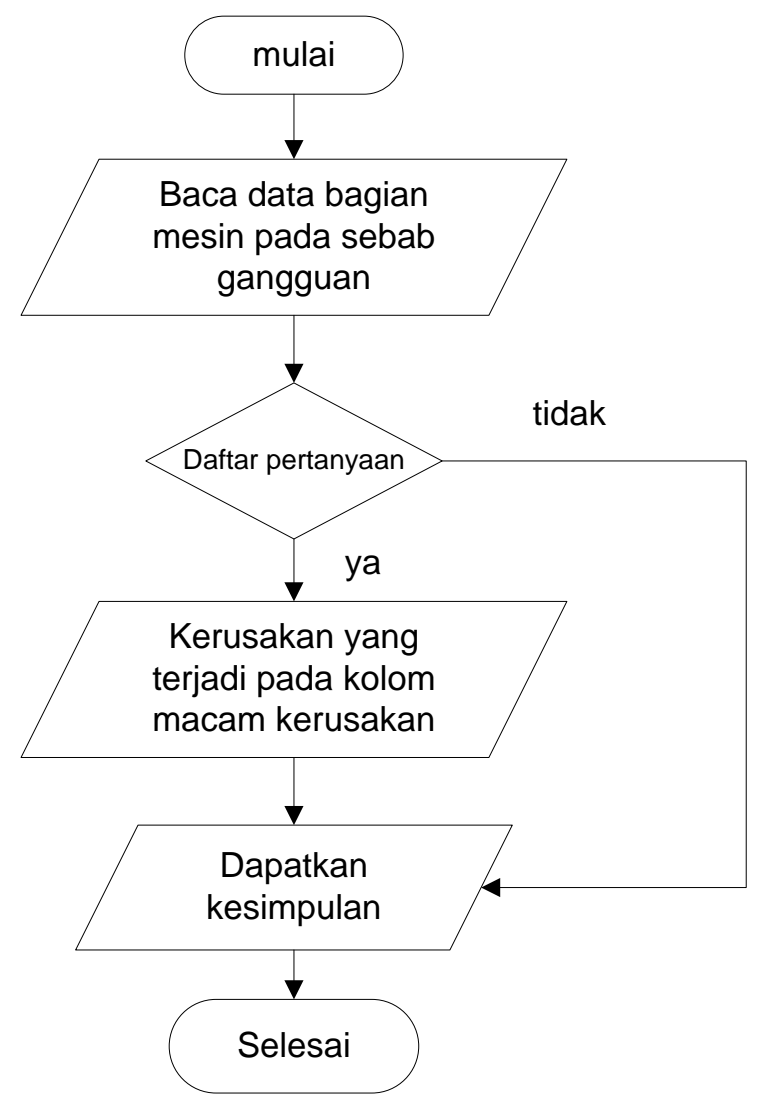

Gambar 3: Bentuk pencarian kesimpulan tentang kerusakan [12]

Tahap pengembangan knowledge base meliputi: 1) mendefinisikan kemungkinan penyelesaian. Dalam tahap ini yang dilakukan adalah menentukan domain pengetahuan ke dalam daftar kemungkinan penyelesaian jawaban, pilihan atau rekomendasi lain; 2) mendefinisikan data masukan. Dalam tahap ini yang dilakukan adalah identifikasi dan mendaftar semua data yang diperlukan system;3) pengembangan garis besar. Dalam tahap ini yang dilakukan adalah menambah domain penyelesaian dan data masukan yang diperlukan untuk mengatasi kesulitan dalam menulis aturan; 4) menggambar pohon pengetahuan, dalam tahap ini yang dilakukan adalah membuat kontruksi sebuah pohon keputusan dan pencarian; 5) membuat matrik knowledge acquisition. Dalam hal ini yang dilakukan adalah membuat akuisisi knowledge base pengetahuan berbentuk sebuah matrik; 6) pengembangan software, dalam hal ini yang dilakukan adalah menulis knowledge base yang sudah ada dan siap digunakan kedalam bahasa yang dimengerti oleh computer [13].

9. Implementasi Database. Hampir semua operasi dalam komputer berhubungan dengan pengolahan data dan sebagian besar program yang berhubungan dengan operasi data pasti menggunakan database sebagai tempat penyimpanan dan pengolahan data. Ada beberapa hal yang objektif yang perlu dipertimbangkan dalam membangun suatu program yang mengolah data dalam jumlah besar, diantaranya adalah: 1) mampu mengeliminasi redudansi data, artinya data tidak perlu ditulis berulang-ulang tetapi hanya informasi singkat yang disimpan dengan benar ditempat yang benar; 2) mampu mencari lokasi atau tempat dimana suatu data disimpan, artinya data dapat dinavigasi dengan baik karena hal ini akan banyak membantu proses pelacakan data; 3) adanya kemudahan dalam mengimplementasikan database sehingga semua kesulitan dalam implementasi program dapat ditekan seminimal mungkin sehingga proses membangun suatu program pengolahan data menjadi lebih mudah [8].

Dalam membangun database terdapat sekumpulan tabel didalamnya yang menyimpan berbagai informasi tentang suatu topik pembahasan. Tabel-tabel tersebut sangatlah penting dalam melakukan proses pengolahan data. Dalam merancang suatu database perlu diperhatikan cara untuk melakukan normalisasi data. Tujuannya untuk mengeliminasi redudansi data [7]. 
Ada beberapa aturan umum yang menjadi pedoman dalam mengorganisasikan data menjadi tabel-tabel yang membentuk database. Pedoman berikut bukanlah pedoman yang mutlak harus diikuti karena dalam banyak hal rancangan suatu database lebih memperhatikan kasus dan bagaimana penyelesaiannya [8].

- Definisikan setiap topik atau bahasan untuk setiap tabel dan pastikan bahwa semua data dalam tabel terhubung dengan topik yang dimaksud.

- Jika ada informasi yang ditulis berulang-ulang dalam suatu tabel, pecahkan tabel tersebut menjadi beberapa tabel kemudian atur hubungan antar tabel sehingga tetap berelasi.

- Jangan menyimpan informasi dalam tabel jika informasi tersebut akan dioperasikan atau dikalkulasi dengan informasi pada tabel lain.

- Gunakan teknik normalisasi data untuk meningkatkan akurasi data yang diinputkan.

10. Perancangan Proses. Perancangan proses akan menjelaskan bagaimana sistem bekerja untuk mengolah data input menjadi data output dengan fungsi-fungsi yang telah direncanakan. Untuk diketahui, bahwa sistem ini akan digunakan oleh dua user, yaitu user umum dan user administrator. Diagram alir sistem user menggunakan metode forward dan backward chaining, serta diagram alir manajemen sistem dalam mengedit data melalui proses tambah, hapus atau update data [7].

11. Perancangan Interface. User interface merupakan bagian dari Virtual Reality yang digunakan sebagai media atau alat komunikasi antar user dan system [14]. Pada user interface ini dibedakan dua user:

- User umum adalah user yang menggunakan Virtual Reality ini untuk mencari informasi dari gangguangangguan yang dialami atau sekedar mencari informasi jenis-jenis kerusakan mesin pada Fin Komodo beserta gejalanya.

- User administrator adalah user yang bertugas untuk melakukan proses editing penambahan dan perawatan data di dalam Virtual Reality jika diperlukan perubahan.

\section{Kesimpulan}

Setelah dilakukan pengujian dan analisis program, maka dapat diperoleh simpulan sebagai berikut:

1. Aplikasi berbasis Android akan mempermudah perusahaan dalam mempromosikan perusahaan karena dapat diakses oleh banyak orang selama 24 jam.

2. Perusahaan dapat dengan mudah dan cepat mengupdate informasi yang akan disampaikan kepada customer tanpa harus menghubungi customer satu persatu

3. Aplikasi yang dibuat dapat membantu pengguna untuk mencari informasi mengenai kerusakan mesin dan informasi terkini dalam bidang otomotif dengan cepat dan mudah.

4. Aplikasi yang dibuat dapat diakses lebih dari satu pengguna pada waktu bersamaan dan mempermudah pengguna tanpa harus ke bengkel untuk konsultasi dengan mekanik.

5. Perawatan juga perlu dilakukan agar program ini dapat digunakan semaksimal mungkin serta perlu dilakukan evaluasi terhadap sistem sehingga dapat dilakukan penyesuian terhapap sistem.

6. Untuk membuat suatu program kecerdasan buatan atau Virtual Reality tidak harus menggunakan bahasa pemrograman Android seperti yang digunakan dalam pembahasan ini, namun dapat juga menggunakan bahasa pemrograman lain yang berorentasi pada objek maupun pemrograman terstruktur.

\section{Daftar Pustaka}

[1] A. Ully, S. Bambang and S. A. Nisfu, "Pembuatan Aplikasi Tata Ruang Tiga Dimensi Gedung Serba Guna Menggunakan Teknologi Virtual Reality," Jurnal Teknik ITS, vol. 1, no. 1, pp. A-540-A-544., 2012.

[2] J. E. Gaskin, Whatever happened to artificial intelligence? The grand promise of intelligent machines underestimated the complexity of reproducing human cognition, New York: Network World, 2008.

[3] B. Shneiderman and C. Plaisant, Designing the User Interface: Strategies for Effective Human-Computer Interaction. Fifth Edition, Cambridge: Addison-Wesley , 2010.

[4] . F. Karray, M. Alemzadeh, J. A. Saleh and M. N. Arab, "Human Computer Interaction: Overview on State of the Art," International Journal on Smart Sensing and Intelligent Systems, vol. 1, no. 1, 2008.

[5] D. Pratiwi and R. Agushinta, Mengenal Interaksi Manusia dan Komputer, Jakarta: PC Plus, 2011.

[6] R. Pressman, Software Engineering: A Practitioner's Approach, 7th Edition, New York: McGraw-Hill., 2010.

[7] S. H. Nazruddin, Pemograman Aplikasi Mobile Smartphone dan Tablet PC Berbasis Android, Bandung: Informatika, 2012. 
[8] Purwoko and B. H. Setyo, "The Development of CNC Virtual Machine as Interactive Media in Learning of CNC Programming," Jurnal Penelitian dan Evaluasi Pendidikan, vol. 13, no. 2, 2015.

[9] A. Firdan, Pengenalan Dasar Android Programming, Depok: Biraynara, 2011.

[10] M. Fernando, Membuat Aplikasi Android AR Menggunakan Vuforia SDK dan Unity, Surakarta: Buku AR Online, 2013.

[11] A. Developers, "Android Developers," 2014. [Online]. Available: http://developer.android.com..

[12] J. DiMarzio, AndroidTM: A Programmer’s Guide, New York: Mc Graw Hill., 2008.

[13] A. Android A sampai Z., Jakarta: PCplus, 2011.

[14] W. M. Lee, Beginning Android Application Development, Cambridge: Wiley Publishing, Inc, 2011.

\section{Biodata Penulis}

1. Hennry Poerwanto Brotoatmodjo, memperoleh gelar Sarjana Arsitektur (Ir.), FT UGM, lulus tahun 1984. Tahun 1998 memperoleh gelar Magister Komputer (M.Kom) dari STTI Benarif Jakarta. Program MM UII Yogyakarta, lulus tahun 1998. Saat ini sebagai Staf Pengajar LLDikti wilayah V DIY DPK pada Universitas Amikom Yogyakarta.

2. Muhammad Taufiq, memperoleh gelar Sarjana Teknik Perminyakan (Ir.) di FT Perminyakan UPN Veteran Yogyakarta lulus tahun 1990. Tahun 2013 memperoleh gelar Magister Komputer (M.Kom) di Universitas Amikom Yogyakarta, saat ini sebagai Dosen Pendidikan Teknologi Informasi (FKIP) Universitas Muhammadiyah Tasikmalaya 